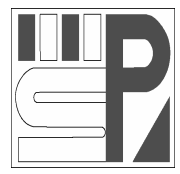

Science Press
Journal of Arid Land

2012, 4(2): 140-150

doi: 10.3724/SP.J.1227.2012.00140

jal.xjegi.com; www.chinasciencejournal.com

\title{
Differences in response of desert plants of different ecotypes to climate warming: a case study in Minqin, Northwest China
}

\author{
ZhaoFeng CHANG ${ }^{1,2,3}$, ShuJuan ZHU ${ }^{1,2,3 *}$, FuGui HAN ${ }^{1,2,3}$, ShengNian ZHONG ${ }^{1,2,3}$ \\ ${ }^{1}$ Minqin National Station for Desert Steppe Ecosystem Studies, Minqin 733300, China; \\ ${ }^{2}$ Gansu Key Laboratory of Desertification Combating, Lanzhou 730070, China; \\ ${ }^{3}$ Gansu Desert Control Research Institute, Lanzhou 730070, China
}

\begin{abstract}
Globally climates are warming. How do desert plants of different ecotypes respond to the climate change? This paper studied the differing responses to climate warming shown by desert plants of different ecotypes through analyzing the phenology and meteorological data of 22 desert plant species growing in Minqin Desert Botanical Garden in Northwest China during the period 1974-2009. The results indicate: (1) The temperature in the study area has risen quickly since 1974, and plants' growing periods became longer. The spring phenology of mesophytes advanced, and the autumn phenology of xerophytes was delayed; (2) The starting dates of spring phenophase of mesophytes and xerophytes differed significantly and both showed an advancing trend; (3) The spring phenology of mesophytes advanced by more days than that of xerophytes, whereas the autumn phenology of mesophytes was delayed by less days than that of the xerophytes; and (4) Mesophytes are more sensitive than xerophytes to rising temperature in spring and falling temperature in autumn. These findings are of value in plant management and regional introduction of different species.
\end{abstract}

Keywords: desert plants; plant phenology; phenophases; ecotypes; climate warming; Minqin

Plant phenology is not only a physiological phenomenon of plant itself, but a comprehensive indicator to the habitat, climate and hydrology in a region. Since its inception, phenology has been an important component and method for studying ecology and climatology (Zhu and Wan, 1980; Wan and Liu, 1987).

Under the context of global warming, the response of plant phenology to climate change is currently a 'hotspot' in phenological research. Studies have mainly concentrated on the response of phenology to climate warming, dealing with issues like advance of spring phenology, delay of autumn phenology and lengthening of plants' growing periods (Bradley et al., 1999; Chmielewski and Thomas, 2001; Menzel, 2002; Matsumoto et al., 2003; Badeck et al., 2004; Menzel et al., 2006). It was found that, from Scandinavia in northern Europe to Macedonia in southeastern Europe, the bud burst of poplars had advanced by 6 days compared to 30 years ago, and leaf coloration in autumn had been delayed by 5 days over the same period (Menzel and Fabian, 1999). Even hens' laying time in England advanced (Crick et al., 1997; Both and Visser, 2001). In Europe, with the temperature rising by $1^{\circ} \mathrm{C}$ in early spring, the growing season advanced by 7 days, and as the mean annual temperature had risen by $1{ }^{\circ} \mathrm{C}$, the growing period lengthened by 5 days (White et al., 1999; Frank et al., 2001). Data for 1959-1996 collected in the Europe International Phenology Garden indicated the spring phenology had advanced by 6.3 days while the autumn phenology had delayed by 4.5 days (Menzel, 2000), which was consistent with the results derived from the Normalized Difference

Received 2011-09-19; accepted 2011-12-26

"Corresponding author: ShuJuan ZHU (E-mail: zhshj1999@163.com) 
Vegetation Index (NDVI) in the area $45-70^{\circ} \mathrm{N}$ during 1982-1990 (Myneni, 1997). Rötzer et al. (2000) analyzed the observed phenological data of 4 spring phenophases from 1951 to 1995 in 10 regions in Middle Europe, and concluded that plant growth periods showed an increasing trend of 1.3-4.0 days per decade. Menzel (2000) analyzed similar data collected during 1951-1996 and concluded that the spring phenology of some species showed a linear advancing trend of 2.1 days per decade; the autumn phenology showed a linear delaying trend of 1.6 days per decade and the growing period displayed a linear lengthening trend of 3.6 days per decade.

American researchers observed that since the 1990s, the flowering periods in southwestern America and northwestern Mexico had experienced an advance in step with the rising temperature (Bowers, 2007). However, both the advancing days of phenology and the lengthening growing periods in America were slightly shorter than those in Europe. The spring phenophase in Europe during 1969-1998 advanced by 8 days (Chmielewski and Thomas, 2001) while that in North America during 1959-1993 advanced by 6 days (Schwartz and Reiter, 2000). The latest NDVI indicates that in the past 20 years, the growing periods of plants have lengthened by 18 days in Eurasia, and by 12 days in North America (Zhou et al., 2001).

Studies on the correlation between climate and growing season variation were mostly conducted in Europe. At the mid-latitudes, plant spring phenology depends mainly on temperature changes (Chmielewski and Thomas, 2001). Plants cannot survive without favorable temperature, and only under certain accumulated temperatures can they complete their life cycle (Menzel, 2000).

Research on plant phenology in desert areas has focused on water physiology. Israeli scholars reported that water stress did not impact the phenology of annual desert plants but influenced their flowering periods. Water stress can accelerate plant degeneration (Aronson et al., 1992). El-Ghani (1997) studied desert plant phenology in Saudi Arabia and Ghazanfar (1997) investigated desert plant phenology in a wadi in northern Oman. Their results indicated that the start and duration of flowering was closely related to precipitation and its duration. The total rainfall didn't affect the flowering period of phanerophytes and chamaephytes, but did affect the start of flowering of annuals and hemicryptophytes. In addition to these studies, few findings concerning the phenology of desert plants are available.

In China, the research on plant phenology has focused on the correlation between phenology and climate warming (Zheng et al., 2002; Ge et al., 2003; Dai et al., 2005a; Bai et al., 2009). The flowering dates of 48 woody species in Beijing during 1990-2007 advanced by 5.4 days in contrast to those during 1963-1989. Among the 48 species, 70.8\% advanced by 7 days, with only one being rather late (Bai et al., 2010). Dai et al. (2005b) revealed that alpine vegetation is more sensitive to climate warming. Based on NDVI, Piao et al. (2006) forecasted that if the mean annual temperature in the temperate forests in China rises by $1^{\circ} \mathrm{C}$, the growing period of plants in spring will advance by 7.5 days and the leaf coloration in autumn will be delayed by 3.8 days.

In recent decades, plant spring phenologies in midand high-latitude have advanced to different extents, which is an indicator of global warming and regional differences (Ge et al., 2010). The $17^{\text {th }}$ International Conference on Biology \& Climate held in German in 2005 suggested that phenology research methods have diversified, and more and more attentions are being paid to the study of comparisons of regional phenological variations (Dai et al. 2006). Yang and $\mathrm{E}$ (2000) made a quantitative analysis of phenological types through studying 46 species of xerophytes, mesophytes and psammophytes growing in the Minqin Desert Botanical Garden. Chang et al. (2008) studied the phenological characteristics of the main plants growing in the Minqin desert area in Northwest China.

Current research on the response of phenology to climatic variation mainly focuses on two aspects: (1) the comparison between plants of the same ecotype; and (2) analyses of the response(s) of one or more species in certain regions to climatic change. Chang et al. (2011) analyzed the phenological responses of different life-form plants to climate warming. No findings concerning the response of desert plants of different ecotypes to climate warming are available.

Plant ecotypes indicate how plants adapt to their eco-environment in the long run. This paper describes 
research undertaken in the Minqin Desert Botanical Garden and attempts to identify how desert plants of different ecotypes (xerophytes and mesophytes) respond to climate change and if they exhibit different responses.

\section{Study area}

The study was conducted at the Minqin Desert Botanical Garden (Fig. 1), which is located at the western fringe of the Tengger Desert in Northwest China $\left(102^{\circ} 59^{\prime} \mathrm{E}, 38^{\circ} 34^{\prime} \mathrm{N}\right)$ and is characterized by an average elevation of $1,378 \mathrm{~m}$, annual mean temperature of $7.76^{\circ} \mathrm{C}$, annual average precipitation of $16.36 \mathrm{~mm}$, annual average evaporation of $2,383.7 \mathrm{~mm}$, and annual average wind speed of $2.4 \mathrm{~m} / \mathrm{s}$. There are 27.4 days with $>17 \mathrm{~m} / \mathrm{s}$ gales within a year. In the Han Dynasty (206 BC-220 AD), there was a large area of water in Minqin. However, desertification appeared since then and the environment was gradually degraded. Currently, the land is covered by undulating sand dunes, with a groundwater table of 16-20 m deep. The natural vegetation is dominated by xerophytic shrubs, semi-shrubs and herbs, with a coverage of lower than $15 \%$.

\section{Materials and methods}

\subsection{Materials}

Minqin Desert Botanical Garden was listed as a member of the national phenology observation net- work by the Institute of Botany, Chinese Academy of Sciences in 1974. Since then, 108 species (20 trees, 48 shrubs and 40 herbs) have been observed, with 15 phenophases for each. However, some species disappeared while others were subsequently supplemented. In this study, 22 species ( 8 trees or small trees, 10 shrubs and semi-shrubs, and 4 herbs) with complete observational data during 1974-2009 (Table 1) were selected for analysis.

Among the species, Artemisia arenaria and Nitraria tangutorum are the representatives of local natural shrubs. Artemisia arenaria is widely distributed at the middle and lower parts of semi-fixed and mobile sand dunes, as well as at interdune depressions. Statistics show

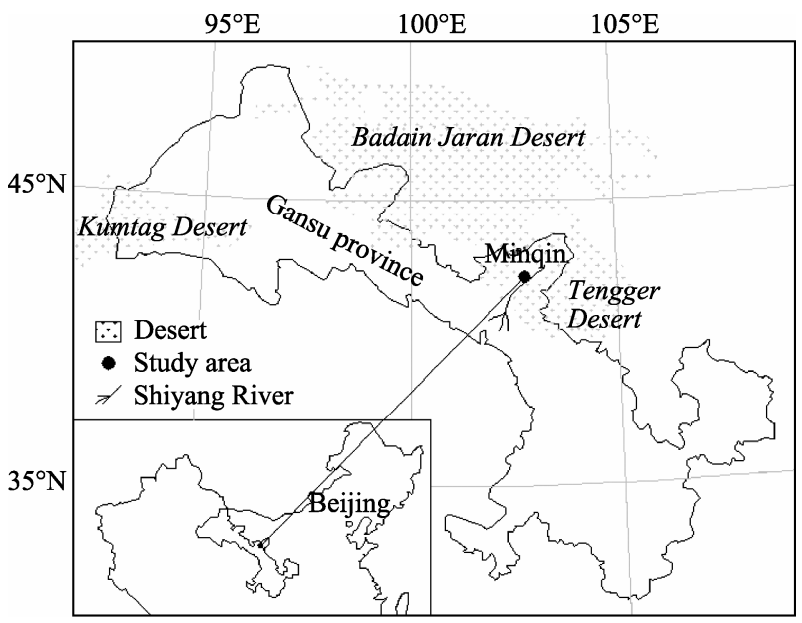

Fig. 1 Location of the study area

Table 1 Species observed in Minqin Desert Botanical Garden

\begin{tabular}{|c|c|c|c|c|}
\hline & Ecotype & Life-form & No. & Species \\
\hline \multirow{9}{*}{ Xerophytes } & \multirow{7}{*}{ Growing in arid environment } & Tree & 1 & Amorpha fruticosa \\
\hline & & \multirow{4}{*}{ Shrub } & 2 & Caragana korshinskii \\
\hline & & & 3 & Caragana intermedia \\
\hline & & & 4 & Tamarix elongata \\
\hline & & & 5 & Lycium ruthenicum \\
\hline & & \multirow[b]{2}{*}{ Herbage } & 6 & Sophora alopecuroides \\
\hline & & & 7 & Glycyrrhiza uralensis \\
\hline & \multirow{15}{*}{ Growing in desert } & Small tree & 8 & Haloxylon ammodendron \\
\hline & & Shrub & 9 & Nitraria tangutorum \\
\hline \multirow{13}{*}{ Mesophytes } & & Shrub & 10 & Artemisia arenaria \\
\hline & & \multirow{6}{*}{ Tree } & 11 & Populus alba var. pyramidalis \\
\hline & & & 12 & Populus gansuensis \\
\hline & & & 13 & Prunus armeniaca \\
\hline & & & 14 & Robinia pseudoacacia \\
\hline & & & 15 & Ulmus pumila \\
\hline & & & 16 & Ziziphus jujuba \\
\hline & & \multirow{4}{*}{ Shrub } & 17 & Forsythia suspense \\
\hline & & & 18 & Syringa oblata \\
\hline & & & 19 & Syringa oblata var.alba \\
\hline & & & 20 & Paeonia suffruticosa \\
\hline & & \multirow{2}{*}{ Herb } & 21 & Medicago sativa \\
\hline & & & 22 & Paeonia lactiflora \\
\hline
\end{tabular}


that the area of Nitraria tangutorum was $6.642 \times 10^{4}$ $\mathrm{hm}^{2}$ in 2002. Haloxylon ammodendron is the pioneering sand-stabilizing species in local areas and currently there is $4.4 \times 10^{4} \mathrm{hm}^{2}$ of planted Haloxylon ammodendron forests in Minqin county. Caragana intermedia and Caragana korshinskii were also planted as sand-stabilizing species. Populus alba var. pyramidalis and Populus gansuensis are the main species for farmland windbreaks.

\subsection{Methods}

Phonological observations were made once every two days during the growing period, with 3-5 individuals observed for each species according to the method of "Chinese Phenological Observation Standard" (Wan and Liu, 1987). The observations covered 15 phenophases (Table 2). Bud expansion was the starting point of phenology while the completion of defoliation was the ending point of phenology. The meteorological data were derived from the ground weather station installed in the Minqin Integrated Desert Control Experiment Station (1.5 km away from the study area). The observations were made following the meteorological observation standards formulated by the Chinese State Meteorology Bureau.

The phenological periods investigated include the stages of bud expansion, leafing, flowering, fruiting, leaf coloring, and defoliation. The former four events are termed as spring phenology and the latter two autumn phonologies. The phenological parameters used include growing season length (from the starting date of bud expansion to the ending date of defoliation), starting date (the time when nearly $50 \%$ of the species have experienced a certain phenological event), ending date (the time when most of the species have fin- ished this event) and duration (days from the starting to the ending of one phenology event) (Yang and E, 2000). Here, budding period refers to the process of buds beginning to develop on a part of the plant, leafing period the process of forming leaves, flowering period the process of plant blooming; fruiting period the process of plants bearing fruits, leaf coloring period the process of color changing on the leaves, and defoliation period the process of leaf falling.

The starting date of a species' growing period was expressed in Julian days (calculated from 1 January of the current year, and similarly hereinafter). Data were analyzed using the SPSS 13.0 software. The trends in variation of air temperature, growing season duration, precipitation and air humidity were expressed with a linear equation with one unknown quantity. The correlations among air temperature, precipitation, air humidity and phenology were expressed with the Pearson correlation coefficient, and relevant significance was tested. The differences of phenological variations between plants of different ecotypes and life-forms were analyzed using a one-way ANOVA.

First, the average dates of plant phenophases for different ecotypes were calculated. Then the differences of certain phenophases between mesophytes and xerophytes were denoted with the regression significance of the variation in their phenology dates. The formula is:

$$
D_{i j}=\left|M_{i j}-X_{i j}\right| \text {. }
$$

Where, $D_{i j}$ is the difference in dates of $i$ phenophase of mesophytes and xerophytes in the year $j ; M_{i j}$ and $X_{i j}$ are the average dates of $i$ phenophase of mesophytes and xerophytes, respectively; $i$ means the starting/ending dates of phenology; the growing period, $j=1,2, \ldots, 36$.

Table 2 Average dates of phenophase incidence

\begin{tabular}{|c|c|c|c|c|c|c|c|c|c|c|c|c|c|c|c|c|}
\hline \multirow[t]{2}{*}{ Ecotype } & & \multicolumn{15}{|c|}{ Phenophase } \\
\hline & & 1 & 2 & 3 & 4 & 5 & 6 & 7 & 8 & 9 & 10 & 11 & 12 & 13 & 14 & 15 \\
\hline \multirow{2}{*}{ Mesophytes } & Mean & $26 \mathrm{Mar}$ & $5 \mathrm{Apr}$ & $22 \mathrm{Apr}$ & $29 \mathrm{Apr}$ & 19 Apr & 1 May & 9 May & 22 May & $19 \mathrm{Jul}$ & $29 \mathrm{Jul}$ & 12 Aug & 1 Oct & 16 Oct & $12 \mathrm{Oct}$ & 27 Oct \\
\hline & SD & 3.8 & 3.1 & 2.9 & 2.5 & 2.8 & 2.6 & 2.3 & 2.5 & 1.7 & 0.9 & 1.3 & 2.4 & 2.5 & 2.2 & 2.1 \\
\hline \multirow{2}{*}{ Xerophytes } & Mean & 7 Apr & 17 Apr & $25 \mathrm{Apr}$ & 5 May & 17 May & 29 May & 8 Jun & 18 Jun & 4 Aug & 14 Aug & $3 \mathrm{Sep}$ & $26 \mathrm{Sep}$ & 13 Oct & 10 Oct & 30 Oct \\
\hline & SD & 3.0 & 2.6 & 2.4 & 2.4 & 2.7 & 2.2 & 1.8 & 2.2 & 1.7 & 1.4 & 1.5 & 4.4 & 3.9 & 3.4 & 3.3 \\
\hline
\end{tabular}

Note: 1, Bud-expansion; 2, Bud-opening; 3, Beginning of leaf extension; 4, Leaf flourishing; 5, Flower-bud appearance; 6, Beginning of flowering; 7, Flower flourishing; 8, End of flowering; 9, Fruit maturity; 10, Beginning of fruit drop; 11, End of fruit drop; 12, Beginning of leaf discoloration; 13, Full leaf-discoloration; 14, Beginning of leaf fall; 15 , End of leaf fall; SD = standard deviation 
The $95 \%$ confidence level was used for significance in tests of regression trend, relevant coefficients and variance.

\section{Results}

During 1974-2009, the temperature in the study area showed a significant increasing trend $(P<0.01)$ (Fig. 2a) at the rate of $0.27^{\circ} \mathrm{C} / 10 \mathrm{a}$; in terms of monthly av-
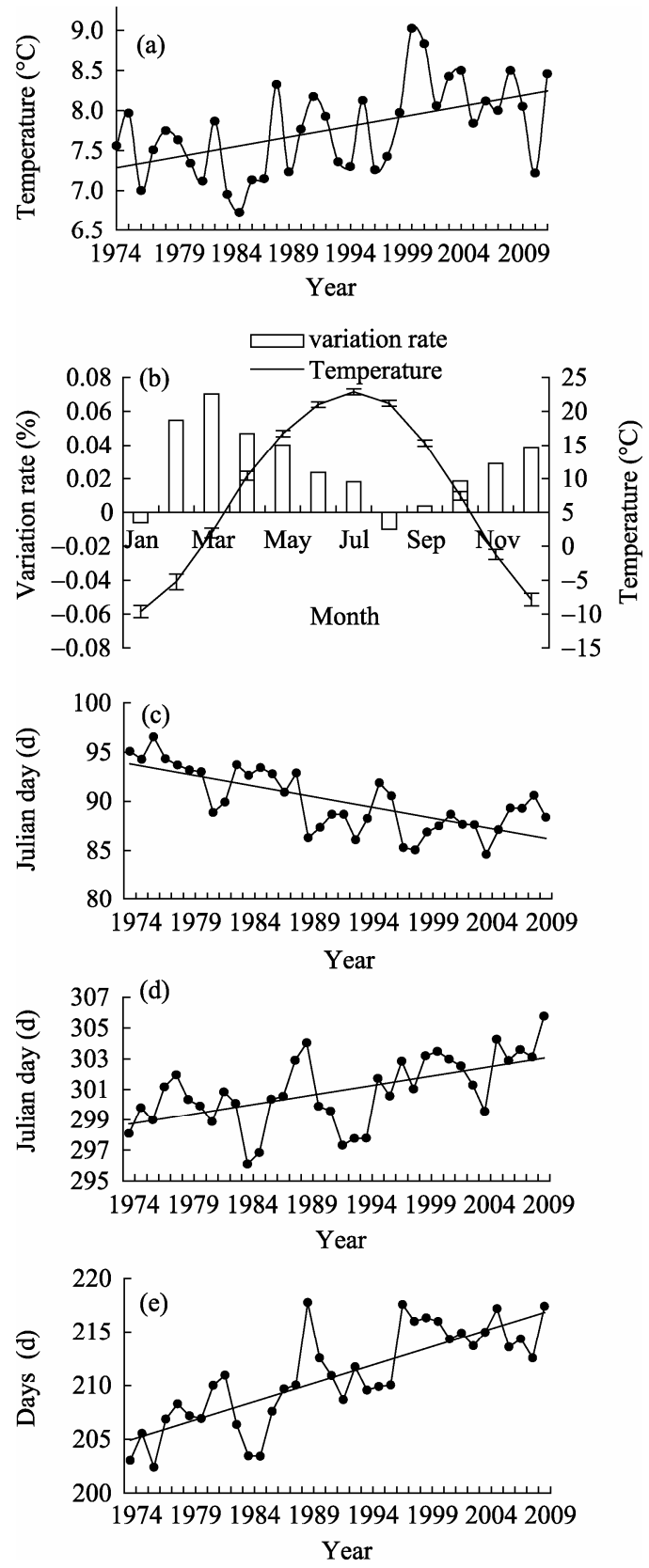

Fig. 2 Variations of temperature and phenology during 1974-2009. (a) Annual mean temperature; (b) Monthly average temperature and the standard deviation; (c) Starting date of spring phenology; (d) Ending date of autumn phenology; (e) Duration of growing period erage temperature, high rates of increase can be found in February, March, April, May and December, whereas the temperatures in January and August showed a decreasing trend (Fig. 2b). Only in March, April, May and July did the temperature show an evident increasing trend $(P<0.05)$.

During 1974-2009, the starting date of spring phenology (throughout this paper taken to be the start of bud-expansion) showed a clear advancing trend $(P<0.01)$ (Fig. 2c), advancing by 7.57 days in 36 years. The ending date of autumn phenology (throughout this paper taken to be the end of leaf-fall) showed a significant delaying trend $(P<0.01)$ (Fig. $2 \mathrm{~d}), 4.33$ days in 36 years. The growing period showed an obvious lengthening trend $(P<0.01)$ (Fig. 2e), 11.9 days in 36 years.

\subsection{Phenological differences between plants of different ecotypes}

During the period 1974-2009, the starting date of spring phenology in mesophytes presented an advancing trend $(P<0.01)$ at the rate of $-0.26 \mathrm{~d} / \mathrm{a}$, with 9.17 days advanced in 36 years; in the same period xerophytes displayed an advancing trend $(P<0.01)$ at the rate of $-0.15 \mathrm{~d} / \mathrm{a}$, with 5.26 days advanced in 36 years (Fig. 3a). In terms of the ending date of autumn phenology, mesophytes showed a delaying trend $(P<0.01)$ at the rate of $0.10 \mathrm{~d} / \mathrm{a}, 3.44$ days delayed in 36 years, while xerophytes presented a delaying trend $(P<0.01)$ at the rate of $0.16 \mathrm{~d} / \mathrm{a}$, or 5.62 days delayed in 36 years (Fig. 3b). In terms of growing season duration, mesophytes showed a lengthening trend $(P<0.01)$ at the rate of $0.36 \mathrm{~d} / \mathrm{a}$, with 12.60 days lengthened in 36 years; xerophytes showed a lengthening trend $(P<0.01)$ at the rate of $0.31 \mathrm{~d} / \mathrm{a}$, or 10.89 days lengthened in 36 years. So the growing season duration of mesophytes was increasing more quickly than that of xerophytes $(P<0.01)$ (Fig. 3c).

During 1974-2009, the starting dates of spring phenology in mesophytes and xerophytes (expressed in Julian day) (Fig. 3a) differed significantly, as did the ending dates of autumn phenology (Fig. 3b) and the growing season duration (Fig. 3c). Both the starting date of spring phenology and the ending date of autumn phenology of mesophytes were significantly earlier than that for xerophytes, and the duration of the growing seasons of mesophytes was significantly 
longer than those of xerophytes. Calculations based on Eq. (1) showed that the difference in the starting dates of spring phenology for mesophytes and xerophytes displayed a significant increasing trend over the years of the observation period $(P<0.05)$, whereas the differences between both the ending dates of autumn phenology and the length of the growing period showed an insignificant trend over the years $(P>0.05)$.
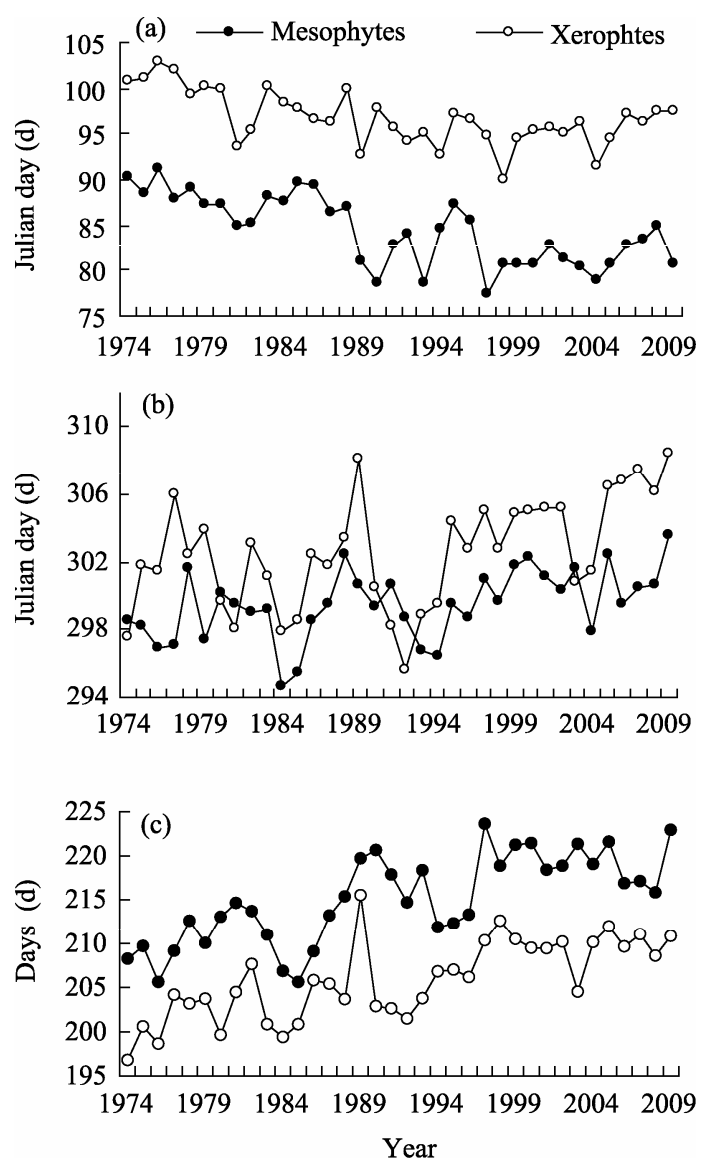

Fig. 3 Differences between mesophytes and xerophytes in terms of the starting date and ending date of phenology as well as the growing period. (a) Starting date of spring phenology (Julian days); (b) Ending date of autumn phenology (Julian days); (c) Duration of growing period

\subsection{Sensitivity of plants' phenology to climate change}

During the period 1974-2009, the phenological changes were characterized by advance of spring phenology and delay of autumn phenology. In the 15 phenophases observed, the advance rate of spring/summer phenology $(P<0.05)$ was in the following order: bud-expansion $>$ bud-opening $>$ flower-bud appearance $>$ the beginning of leaf extension and leaf flour- ish $>$ the beginning of flowering $>$ flower-flourishing $>$ the end of flowering $>$ fruit maturity; the delay rate of autumn phenology $(P<0.05)$ was in the order: full leaf-discoloration $>$ beginning of leaf-fall $>$ the beginning of leaf-discoloration $>$ the end of leaf-fall $>$ the end of fruit-drop. In the 15 phenophases, the changing rate of the beginning of fruit-drop over years was the smallest, with an insignificant regression trend $(P>0.05)$, whereas that of the end of fruit-drop and the beginning of coloration were comparatively small, with a significant regression trend $(P<0.05)$; the variation of remaining phenophases showed a significant regression trend $(P<0.05)$ (Fig. 4). Spring and winter phenologies are therefore the sensitive ones.

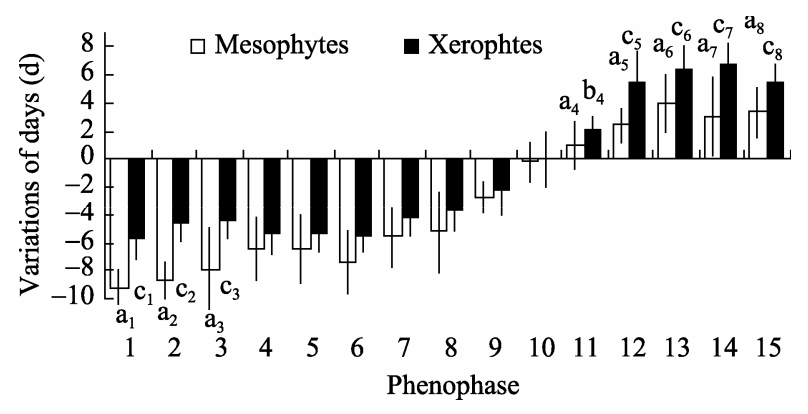

Fig. 4 Difference between mesophytes and xerophytes in terms of phenological variation during 1974-2009

The difference between the phenology of mesophytes and xerophytes was evident in spring and winter. The difference between mesophytes and xerophytes regarding the advance of bud-expansion, bud-opening and leaf-extension was extremely significant $(P<0.01)$; the delay of the beginning of full leaf-coloration, full leaf-coloration, beginning of leaf-fall and end of leaf-fall were extremely significant $(P<0.01)$; the delay of the end of fruit-drop was significant $(P<0.05)$ (Fig. 4).

\subsection{Periodic variation of the response of plants' phenology to climate change}

The starting date of spring phenology (Julian days), the ending date of autumn phenology (Julian days) and the 5-year sliding average of the growing period of mesophytes and xerophytes during 1974-2009 were calculated (Figs. 5a-c). It showed: the starting date of spring phenology, the ending date of autumn phenology and the growing period of mesophytes did not 
well correspond to those of xerophytes. During the period 1974-2009, the starting date of spring phenology of mesophytes experienced 6 stages, whereas that of xerophytes experienced 7 stages (Fig. 5a); the ending date of autumn phenology of both mesophytes and xerophytes experienced 7 stages (Fig. 5b); the growing duration of mesophytes experienced 6 stages, whereas that of xerophytes experienced 7 stages (Fig. 5c).

The turning points of the starting dates of spring phenology, ending dates of autumn phenology and the growing periods of mesophytes and xerophytes were not completely the same (Table 3 ).

Observation of starting dates of spring phenology for mesophytes and xerophytes and their ending dates of autumn phenology and growing periods suggest: (1) plants' autumn phenology, especially that of mesophytes, experienced small changes over the years of observation; and (2) plants' growing periods, especially those of mesophytes, experienced comparatively big changes over the years (Table 4).

\subsection{Correlation between air temperature and the phenological changes of desert plants of dif- ferent ecotypes}

\subsubsection{Difference in plant phenology}

The number of species whose 15 phenophases were correlated with air temperature $(P<0.05)$ was calculated (Fig. 6). The results showed much more species were correlated with the temperature in the concurrent month, and less species were correlated with the annual temperatures and the temperature in the preceding month. Spring (from April to early May) was the first peak, and autumn (from late September to late October) was the second peak, during which the phenology was affected by the temperature. Comparison of the relationship between mesophyte/xerophyte and temperature variation showed: air temperature in spring exerted more impact on the phenology of mesophytes than on that of xerophytes. The five phenophases (i.e. beginning of bud-expansion, bud-opening, leaf-extension, leaf flourishing and
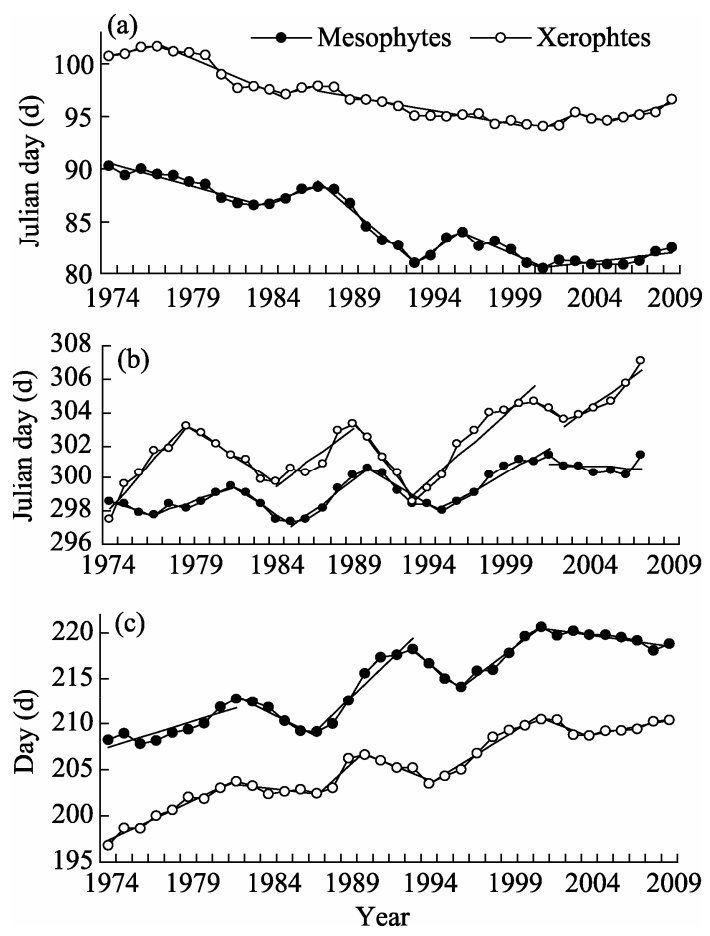

Fig. 5 Periodic differences of the responses of plants' phenology to climate change. (a) Starting date of the phenology; (b) Ending date of the phenology; (c) Growing duration

Table 3 Periodic changes of plant phenology

\begin{tabular}{|c|c|c|c|c|c|c|}
\hline \multirow{2}{*}{ Ecotype } & \multicolumn{2}{|c|}{ Starting of spring phenology } & \multicolumn{2}{|c|}{ Ending of autumn phenology } & \multicolumn{2}{|c|}{ Growing duration } \\
\hline & Years of advance & Years of delay & Years of advance & Years of delay & Years of shortening & Years of lengthening \\
\hline Mesophytes & $\begin{array}{l}1977-1985 \\
1987-2001 \\
2003-2005\end{array}$ & $\begin{array}{l}1974-1977 \\
1985-1987 \\
2001-2003 \\
2005-2009\end{array}$ & $\begin{array}{l}1974-1977 \\
1982-1986 \\
1991-1996 \\
2003-2009\end{array}$ & $\begin{array}{l}1977-1982 \\
1986-1991 \\
1996-2003\end{array}$ & $\begin{array}{l}1982-1987 \\
1993-1996 \\
2001-2009\end{array}$ & $\begin{array}{l}1974-1982 \\
1987-1993 \\
1996-2001\end{array}$ \\
\hline Xerophytes & $\begin{array}{l}1974-1983 \\
1987-1993 \\
1996-2001\end{array}$ & $\begin{array}{l}1983-1987 \\
1993-1996 \\
2001-2009\end{array}$ & $\begin{array}{l}1979-1985 \\
1990-1994 \\
2002-2004\end{array}$ & $\begin{array}{l}1974-1979 \\
1985-1990 \\
1994-2002 \\
2004-2009 \\
\end{array}$ & $\begin{array}{l}1982-1987 \\
1990-1994 \\
2001-2004\end{array}$ & $\begin{array}{l}1974-1982 \\
1987-1990 \\
1994-2001 \\
2004-2009 \\
\end{array}$ \\
\hline
\end{tabular}

Table 4 Standard deviation (SD) of the starting/ending date of phenology and the growing periods of mesophytes and xerophytes

\begin{tabular}{cccc}
\hline Ecotype & $\begin{array}{c}\text { SD of starting } \\
\text { date }\end{array}$ & $\begin{array}{c}\text { SD of ending } \\
\text { date }\end{array}$ & $\begin{array}{c}\text { SD of growing } \\
\text { period }\end{array}$ \\
\hline Mesophytes & 3.34 & 1.23 & 4.35 \\
Xerophytes & 2.44 & 2.12 & 3.82 \\
\hline
\end{tabular}

flower-bud appearance) of $95.0 \%$ mesophytes, compared with $88 \%$ for xerophytes, were correlated with the temperature in the month of the phenophase in mesophytes. Air temperature in autumn exerted more impact on the phenology of xerophytes than on that of mesophytes. And the four phenophases (i.e. beginning 


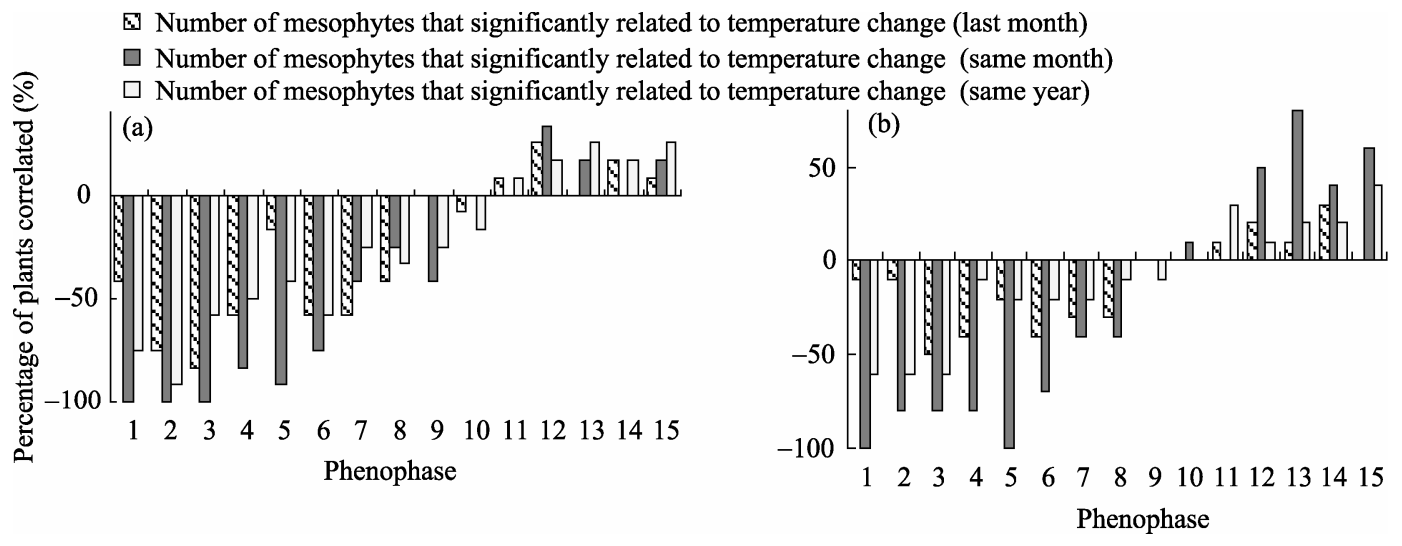

Fig. 6 Percentage of plants whose phenology is significantly correlated with climate change during 1974-2009. (a) Correlation between mesophyte phenology and climate change; (b) Correlation between xerophyte phenoplogy and climate change. Note: the negative values on the $\mathrm{Y}$ axis refer to the negative correlation.

of leaf-coloration, full leaf-coloration, beginning of leaf-fall and end of leaf-fall) of $57.5 \%$ xerophytes, compared with $16.7 \%$ for mesophytes, were correlated with the temperature in the month of the phenophase in xerophytes. For mesophytes, the beginning of bud-expansion, bud-opening and leaf-extension were most sensitive to the air temperature in the concurrent month; for xerophytes, the beginning of bud-expansion and flower-bud appearance were most sensitive to the air temperature in the concurrent month. For mesophytes, the beginning and end of fruit-drop were least sensitive to the air temperature in the concurrent month; for xerophytes, fruit maturity and the beginning of fruit-drop were least sensitive to the air temperature in the concurrent month.

\subsubsection{Differences in plants' growing period}

Only in October and November were there differences between mesophytes and xerophytes in terms of the impact of air temperature on the plants' growing periods. Mesophytes' growing periods were significantly and positively correlated with the temperature in November $(P<0.05)$, whereas the growing periods for xerophytes were significantly and positively correlated with the temperature in October $(P<0.05)$. Both mesophytes' and xerophytes' growing periods were significantly and positively correlated with the temperatures in February, March, April, May, June, July and December as well as the annual average temperature $(P<0.01)$.

The phenology of mesophytes normally started on 26 March, and ended on 27 October; and that of xero- phytes normally started on 7 April, and ended on 30 October (Table 2). Mesophytes' growing periods were mostly positively correlated with the average temperature in March $(R=0.819, P<0.01)$ (Fig. 7a), and secondly positively correlated with the annual average temperature ( $R=0.782, P<0.01$, Fig. $7 b$ ). Xerophytes' growing periods were most positively correlated with the annual average temperature $(R=0.699, P<0.01)$ (Fig. 7c), and less positively correlated with the temperature in May $(R=0.692, P<0.01)$ (Fig. $7 \mathrm{~d})$.

\section{Discussion}

Since 1974, the temperature in the study area has shown a significant rising trend, and the duration of these rising temperatures is longer than that reported in available literature. Over the period 1974-2009, the duration of plant growing seasons has been longer than that reported in available literature. Both the advancing days of spring phenology of mesophyte species and the delaying of autumn phenology amongst xerophyte species were longer than those reported in the literature.

Desert in the Minqin area is covered by large areas of exposed sandy land, and is devoid of vegetation. The specific heat of sand is $0.9 \times 10^{5} \mathrm{~J} /\left(\mathrm{kg} \cdot{ }^{\circ} \mathrm{C}\right), 1 / 4.7$ of that of water, which is $4.2 \times 10^{5} \mathrm{~J} /\left(\mathrm{kg} \cdot{ }^{\circ} \mathrm{C}\right)$; whereas the coefficient of heat conductivity of sand grains is 0.03 $\mathrm{W} /(\mathrm{m} \cdot \mathrm{K}), 1 / 19$ of that of water, which is $0.58 \mathrm{~W} /(\mathrm{m} \cdot \mathrm{K})$. Therefore, the temperature on the sand rises rapidly, and can reach over $70^{\circ} \mathrm{C}$ in summer (Chang and Zhao, 2006). The exposed sandy land can reflect large 

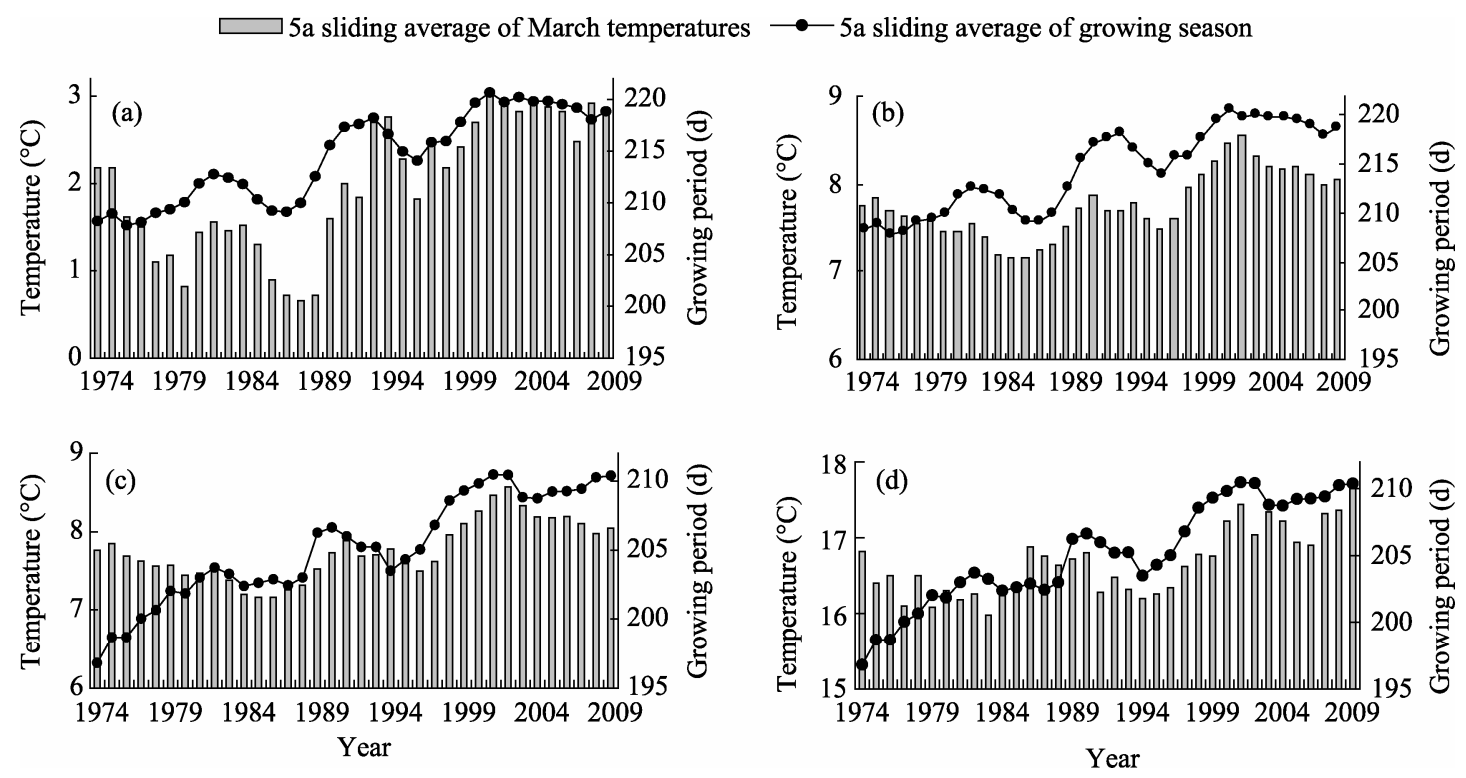

Fig. 7 Correlation between plants' growing periods and temperature variation. (a) Correlation between mesophytes' growing periods and temperatures in March; (b) Correlation between mesophytes' growing periods and annual average temperatures; (c) Correlation between xerophytes' growing periods and annual average temperatures; (d) Correlation between xerophytes' growing periods and temperatures in May

amounts of sun radiation into the near-ground atmosphere. As a result, temperatures rise rapidly in spring, which has contributed to the sensitive response of the sandy desert to global warming.

The growing period of local plants starts from late March to early April and ends in late October. The temperatures in May, June and July are significantly and positively correlated with the growing periods of mesophytes and xerophytes. However, the rising temperature during this period is not directly related to the extension of the growing period. The positive correlation can be regarded as a positive similarity between rising temperature and extension of the growing period.

The higher the renewal buds are located, the more sensitive the plant will be in terms of its spring phenology in responding to the temperature rising in the concurrent month/year (Chang et al., 2011). Table 1 shows that many of the mesophytes chosen for observation grew higher than the xerophytes, which manifests an earlier start of their spring phenology.

Xerophytes have a low sensitivity to environmental change as they grow in arid environments (Chang and Zhao, 2006), whereas mesophytes are comparatively more sensitive to temperature change. Therefore, xerophytes are less responsive than mesophytes to temperature rising in spring and temperature dropping in autumn; the starting date of spring phenology and the ending date of autumn phenology for xerophytes are later than those of mesophytes.

Three species of psammophyte, Haloxylon ammodendron, Nitraria tangutorum and Artemisia arenaria were included in this study. Among these, the starting date of Artemisia arenaria's spring phenology (on 16 March) was earlier than that of the other two, which may be a unique property of the species; whereas the starting date of spring phenology and the ending date of autumn phenology of Haloxylon ammodendron and Nitraria tangutorum were later than those of the xerophytes (Table 5). Accordingly, it can be concluded that in responding to temperature variation, the starting of spring phenology and the ending of autumn phenology of mesophytes were more sensitive than those of xerophytes, and xerophytes were more sensitive than psammophytes. As few psammophytes were included in this study, the conclusion above needs to be further tested.

Xerophytes are less responsive than mesophytes to temperature variations in early spring and late autumn. This is consistent with the properties of mesophytes and xerophytes in adapting to low temperatures. This conclusion will be of certain value in vegetation management and species introduction. 
Table 5 Average dates of phenophase incidence of Haloxylon ammodendron and Nitraria tangutorum

\begin{tabular}{cccc}
\hline Phenophase & Date & Phenophase & Date \\
\hline 1 & $9 \mathrm{Apr}$ & 9 & 1 Sep \\
2 & $18 \mathrm{Apr}$ & 10 & $14 \mathrm{Sep}$ \\
3 & $28 \mathrm{Apr}$ & 11 & $30 \mathrm{Sep}$ \\
4 & $6 \mathrm{May}$ & 12 & $27 \mathrm{Sep}$ \\
5 & 12 May & 13 & 15 Oct \\
6 & 20 May & 14 & 12 Oct \\
7 & 30 May & 15 & 1 Nov \\
8 & 9 Jun & & \\
\hline
\end{tabular}

Note: $1-15$ denote the same meanings as in Table 2.

\section{Conclusion}

The starting dates of spring phenology, the ending dates of autumn phenology and the growing periods of observed mesophytes were significantly different from those of xerophyte species monitored in this study; the starting date of spring phenology and the ending date of autumn phenology of mesophytes were significantly earlier than those of xerophytes, and mesophytes'

\section{References}

Aronson J, Kige J, Shmida, et al. 1992. Adaptive phenology of desert and Mediterranean populations of annual plants grown with and without water stress. Oecologia, 89: 17-26.

Badeck F W, Bondeau A, Böttcher K, et al. 2004. Responses of spring phenology to climate change. New Phytologist, 162: 295-309.

Bai J, Ge Q S, Dai J H. 2009. Response of woody plant phenophases to climate change for recent 30 years in Guiyang. Geographical Research, 28(6): 1606-1614

Bai J, Ge Q S, Dai J H, 2010. The response of first flowering dates to abrupt climate change in Beijing. Advances in Atmospheric Sciences. doi: 10.1007/s00376-010-9219-8.

Both C, Visser M E. 2001. Adjustment to climate change is constrained by arrival date in a long-distance migrant bird. Nature, 411, 296-298.

Bowers Janice E. 2007. Has climatic warming altered spring flowering date of Sonoran desert shrubs? The Southwestern Naturalist, 52(3): $347-355$

Bradley N L, Leopold A C, Ross J, et al. 1999. Phenological changes reflect climate change in Wisconsin. Proceedings of Natural Academy of Sciences of the United States of America, 96: 9701-9704.

Chang Z F, Zhao M, 2006. Study on Desert Ecology in Minqin. Lanzhou: Gansu Science and Technology Press, 30-64.

Chang Z F, Zhao M, Han F G, et al. 2008. Phenological characteristics of desert plants in Minqin desert area. Scientia Silvae Sinicae, 44(5): 58-64. growing periods were also significantly longer than those of xerophytes.

There were extremely significant differences between mesophytes and xerophytes in terms of the advancing days of such 3 phenophases as bud-expansion, bud-opening and the beginning of leaf-extension; similar differences existed in terms of the delaying days of such 4 phenophases as beginning of leaf-discoloration, full leaf-discoloration, beginning of leaffall and end of leaf- fall; and the difference in terms of the delay in the end of fruit-drop was significant. Mesophytes are more sensitive than xerophytes to temperature rising in spring, and to temperature dropping in autumn.

\section{Acknowledgement}

This work was supported by the Pre-phase Project of the State 973 Program (2011CB411912) and Gansu Natural Science Fund Project.

Chang Z F, Wang Q Q, Han F G, et al. 2011. Phenological responses of different life form plants in Minqin desert area to climate warming. Journal of Ecology, 39(9): 1921-1929.

Chmielewski F M, Thomas R. 2001. Response of tree phenology to climate change across Europe. Agricultural and Forest Meteorology, 108(2): 101-112.

Crick H Q P, Dudley C, Glue D E, et al. 1997. UK birds are laying eggs earlier. Nature, 388: 526.

Dai J H, Ge Q S, Zheng J Y, et al. 2005a. An analysis on the relationship between recent warming and changes of plants phenophases in Beijing. Annalen der Meterologie, 41(2): 543-546.

Dai J H, Pan Y, Cui H T, et al. 2005b. Impacts of climate change on alpine vegetation on Wutai Mountains. Quaternary Sciences, 25(2): 216-223.

Dai J H, Zheng J Y, Ge Q S. 2006. Hotspot of the current bio-meteorology research-the $17^{\text {th }}$ international bio-meteorology conference held in Garmisch.Partenkerche. Geologica Sinica, 61(2): 223.

El-Ghani M M A. 1997. Phenology of ten common plant species in western Saudi Arabia. Journal of Arid Environments, 35: 673-683.

Ge Q S, Zheng J Y, Zhang X X, 2003. Research on the climate and phenological changes in China in the past 40 years. Natural Sciences Process, 13(10): 1048-1053.

Ge Q S, Dai J H, Zheng J Y. 2010. The progress of phenology studies and challenges to modern phenology research in China. Bulletin of Chinese Academy of Sciences, 25(3): 310-316. 
Ghazanfar S A. 1997. The phenology of desert plants: a 3-year study in a gravel desert wadi in northern Oman. Journal of Arid Environments, 35: 407-417.

Matsumoto K, Ohta T, Irasawa M, et al. 2003. Climate change and extension of the Gingko biloba L. growing season in Japan. Global Change Biology, 9: 1634-1642.

Menzel A, Fabian P. 1999. Growing season extended in Europe. Nature, 397: 659 .

Menzel A. 2000. Trends in phenological phases in Europe between 1951 and 1996. International Journal of Biometeorology, 44(2): 76-81.

Menzel A. 2002. Phenology: its importance to the global change community. Climate Change, 54: 379-385.

Menzel A, Sparks T H, Estrella N C, et al. 2006. European phenological response to climate change matches the warming pattern. Global Change Biology, 12: 1969-1976.

Myneni R B. 1997. Increase plant growth in the northern high latitudes from 1981 to 1991. Nature, 386: 698.

Piao S L, Fang J Y, Zhou L M. 2006. Variations in satellite-derived phenology in China's temperate vegetation. Global Change Biology, (12): $672-685$.

Rötzer T, Wittenzeller M, Haechel H, et al. 2000. Phenology in central Europe: differences and trends for spring phenophases in urban and rural areas. International Journal Biometeorolkgy, 44(2): 60-66.
Schwartz M D, Reiter B E. 2000. Changes in North American spring. International Journal of Climatology, 20: 929-932.

Wan M W, Liu X Z. 1987. The Observation Methods of Phenology in China. Beijing: Science Press.

White M Z, Running S W, Thornton P E. 1999. The impact of growing season length variability on carbon assimilation and evapotranspiration over 88 years in the eastern US deciduous forest. International Journal Biometeorology, 42(3): 139-145.

Yang Z H, E Y H. 2000. A phenology research on the main xylophyte in arid desert area-an example on cultivated plants of Minqin Desert Botanical Garden. Acta Botanica Boreali-Occidentalia Sinica, 20: 1102-1109.

Zheng J Y, Ge Q S, Hao Z X. 2002. Impacts of climate warming on plants phenophases in China for the last 40 years. Chinese Science Bulletin, 47(20): 1582-1587.

Zhou L, Tucker C J, Kaufmann R K. 2001. Variation in northern vegetation activity inferred from satellite data of vegetation index during 1981 to 1999. Journal of Geophysical Research, 106(D17): 20069-20083.

Zhu K Z, Wan M W. 1980. Phenology. Beijing: Science Press.

Zhu S J, Chang Z F. 2011. Temperature and precipitation trends in Minqin desert during the period of 1961-2007. Journal of Arid Land, 3(3): 214-219. 